\title{
Factors Affecting the Learning Responsibility of First Year Students at Suratthani Rajabhat University
}

\author{
Kiattisak Duangjan ${ }^{1}$ \\ ${ }^{1}$ Faculty of Humanities and Social Sciences, Suratthani Rajabhat University, Khun Taleay, Muang Surat Thani, \\ Thailand \\ Correspondence: Kiattisak Duangjan, Faculty of Humanities and Social Sciences, Suratthani Rajabhat University, \\ 272 Moo 9 Surat-Nasan Road, Khun Taleay, Muang Surat Thani, Thailand. E-mail: \\ kaittisakhuman@outlook.co.th
}

Received: October 15, 2013 Accepted: December 7, 2013 Online Published: January 27, 2014

doi:10.5539/ass.v10n3p79

URL: http://dx.doi.org/10.5539/ass.v10n3p79

\begin{abstract}
This research aimed to study the level of learning responsibility of first-year students at Suratthani Rajabhat University and to compare learning responsibilities of first-year students at Suratthani Rajabhat University. The students were separated by gender, age, religion, faculty and academic discipline. The research samples were first-year students in the first semester of the 2011 academic year at Suratthani Rajabhat University, who were selected by using a Krejcie \& Morgan Table with not more than 5\% error. A total of 354 samples were randomly selected with Proportional Stratified Random Sampling method from three academic disciplines. These disciplines were humanities and social sciences, science and technology and the group of health sciences. A two-part questionnaire was used to collect data, which was analyzed by frequency, percentage, mean and standard deviation. Hypotheses testing and validation was conducted by t-test, F-test, One Way ANOVA and Scheffe's test. The research results found that level of learning responsibility of first-year students at Suratthani Rajabhat University was generally at a high. The students placed importance on understanding new knowledge by using past experiences. Sensibility and ability to work with others effectively was given least importance but remained at a high level. The comparison of learning responsibilities of first-year students at Suratthani Rajabhat University found that gender, age, religion, faculty and academic discipline caused differences in students' views on learning responsibility by a significance level of .05
\end{abstract}

Keywords: responsibility, university, learning, morals, ethics

\section{Introduction}

The rapid advances in technology have caused the economy, politics, energy and the environment to change accordingly, especially with the current of globalization. This has had a knock-on effect to Thai society, communities and the basic values of everyday life. Changes have also been seen in culture, customs, traditions, which have created social problems and imbalances in physical and mental development (Tessana, 2003). The crisis of deteriorating morality and ethics must be confronted through education. At the same time, morality and education are equal tools in developing human qualities (Janbanjong, 1998). Therefore, education management in higher education institutions is the vital heart of development in order to create impartial access to resources, build awareness of democratic values and good governance, and encourage ethics and morals in learners, the youth and all groups of Thai people. This corresponds to tenth edition of the higher education development plan (2008-2011), which stated that during education of youth or post-high school students, professional skills must be instilled that are desirable for the future and related to communication, teamwork, problem solving, responsibility for oneself and others, continuous study, personal management, ethics and values (Office of the Higher Education Commission, 2008). These ideas are further supported by the 1999 Royal Education Act amendments of 2002, volume 2, section 28, paragraph 2, which indicated that the essence of academic and professional curriculums must aim to develop qualities of knowledge, thinking, ability, virtue and social responsibility (Office for National Education Standards and Quality Assessment (Public Organization), 2004). Only people with a moral conscious and sense of responsibility can conduct their own affairs so that they have an appreciable and pleasing outcome and they are an important source of power in supporting the continued advancement of the Thai nation (Chainiyom, 1999). 
Responsibility is a basic, important value of ethics and is a behavioral trait that should be encouraged in order to develop personal quality. Responsibility occurs from the acceptance of learning, experiences and real practice because it is necessary for youth and higher education students. This characteristic must be instilled together with the teaching of knowledge. The research and development of indicators of values and ethics by Nonglak Wirachai, Chayut Piromsombat and Sujeemat Na Wichian (2007) found that university students have fairly low levels of responsibility and lack these values more than in other areas. Students are unpunctual, do not meet work deadlines, skip classes, fail to meet professors on schedule and violate university regulations. Thus, responsibility must be instilled in university students as the most important behavioral trait and it should be the role of university employees to incorporate the training of responsible ethics into their transmission of knowledge so that graduates are encouraged to possess responsibility together with academic skill. This must cover the discipline of students regarding their personal conduct, practice of customs and conventions, respect of regulations, requirements, occasions and social manners. The students must fulfill their social duties, be independent and exercise abilities of self-control. However, in the past it has been found that the majority of students do not behave appropriately and a large number lack morals, ethics and responsibility towards themselves, society and the educational institution. The reasons for this are the problems of narcotic drugs, gambling, nightlife, preoccupation with the opposite gender, and social and academic competition. Additionally, the students have an isolated lifestyle, no time to think of others and interest in themselves more than the community. Therefore, it is necessary to develop these areas in order to change the management of activities that create responsibility and discipline in students, so to build better behavioral characteristics. Moreover, there is a need to design new ways to develop students to have knowledge in tandem with real morals.

Suratthani Rajabhat University is a higher education institute that was established as a university in 2004. Its mission is to produce excellent academic graduates on the foundation of local, national and international wisdom. These graduates must be provided with knowledge as well as morals, ethics, Thai consciousness, love and connection to the local area and upon graduation they should continuously support learning in the community. The university provides an opportunity for all people who are interested in studying at bachelor, masters and doctorate level, especially seven academic areas at bachelor level, which are the faculty of education, faculty of humanities and social sciences, faculty of science and technology, faculty of management science, faculty of nursing and faculty of law. There is also an international college of tourism, which has an equal number of students to the faculties. The university is responsible for the management of education according to its mission. Nowadays, aside from subject teaching, there is guidance of morals and ethics through the media of course curriculums and extra-curricular activities. However, the majority of students are not as interested in attending current activities to encourage moral and ethical behavior as much as they should be. Apart from the events that are made compulsory by the university, the students only attend those activities that they are interested in or personally involved with. The students lack responsibility towards their studies, as is seen by their poor class attendance, lack responsibility towards the institution, made visible by their inability to follow university dress code, and lack responsibility towards society, as made clear by their participation and team work skills. These faults are especially apparent in first-year students, for whom it is important to adapt to new methods of learning and education. If this group has no responsibility towards learning, it may affect their educational progress or make them unable to successfully complete their studies. Therefore, responsibility is a characteristic that must be instilled in the university students and has an important role in the development of education. It is particularly necessary create awareness of responsibility in students with regards all areas of their university lives. This is in accordance with the context of developing graduates with admirable characteristics and the mission statement of Suratthani Rajabhat University.

From the reasons and importance for the problems given above, responsibility is an important ethical trait that must be encouraged and developed in higher education students because the chances of enjoying success in studies and work depend on an individual's responsibility towards that work. This is why the researcher, on behalf of the academic employees of Suratthani Rajabhat University, was interested in studying factors affecting the learning responsibility of first year students at Suratthani Rajabhat University. The results of this research will outline the status of student responsibility and highlight factors that encourage responsibility towards studies. Additionally, the research results will provide a knowledge base for individuals concerned with the development of students and can be used in organizing activities to instill responsibility in students so that they are prepared for their studies, possess desirable graduate characteristics according to the mission of the university and become good people for society and Thailand.

\section{Research Aims}

This research, Factors affecting the learning responsibility of first year students at Suratthani Rajabhat 
University, had two principal aims, which were to study the level of learning responsibility of first-year students at Suratthani Rajabhat University and to compare learning responsibilities of first-year students at Suratthani Rajabhat University.

\section{Methodology}

This research, factors affecting the learning responsibility of first year students at Suratthani Rajabhat University, aimed to study and compare the level of learning responsibility of first year students at Suratthani Rajabhat University according to gender, age, religion and academic discipline of study. The population for this research was comprised of general first-year undergraduate students during term one of the 2011 education year at Suratthani Rajabhat University. The population totaled 4,727 people and was used as the basis for generating sample groups. The sample groups were sized according to the principles of Krejcie and Morgan (1970), with a $95 \%$ confidence level and 5\% margin of error. A sample group of 354 individuals was selected using a proportional stratified random sampling technique. The sample group was divided into three sub-divisions based on academic discipline studied: humanities and social sciences; science and technology; health sciences. After this had been completed, a simple random sample was taken to collect data from the students.

A questionnaire created by the researcher was used as a research tool during this investigation. There were two parts to the questionnaire. The first part contained a set of five close-ended response questions about the informants, which concerned gender, age, religion, faculty and academic discipline of study. The second part of the questionnaire contained questions set on a rating scale about the learning responsibilities of first year undergraduates at Suratthani Rajabhat University. There were twenty-five questions in this part and five choices were given for each question using Likert's Scale (Likert, 1932).

For data collection and analysis, the researcher enlisted help from the Suratthani Rajabhat University Division of Student Affairs in collecting data and responding to the researcher within the agreed timeframe. The results of the questionnaire were then validated before analysis and extrapolation of meaning. Statistical analysis was then conducted on computer using SPSS for Windows in order to determine frequency, percentage, mean and standard deviation of the data. The thoughts about learning responsibilities among first year undergraduate students at Suratthani University were then compared according to gender, age, religion, faculty and academic discipline. Inferential statistics were used in order to conduct comparison and limits were determined using t-test, F-test, one-way ANOVA and when differences were found with the data, these were examined using Scheffe's test (1959). The results were evaluated in statistical analysis tables for presentation and interpretation.

\section{Results}

\subsection{Close-ended Responses Obtained from First Year Undergraduate Students at Suratthani Rajabhat University According to Gender, Age, Religion, Faculty and Academic Discipline}

For this research, 189 of the students in the sample were female and 165 were male. That is $53.39 \%$ female and $46.61 \%$ male. The majority, 301 individuals, were nineteen years old, which equates to $85.03 \%$. 23 people were over nineteen years in age, which was the smallest group of people at $6.50 \% .248$ people, a total of $70.06 \%$ are Buddhist, which is the largest group. The smallest religious group was the category of 'other', which constituted Christians and Hindus. There were four people (1.13\%) in this group. The majority of people in the sample came from the faculty of management science, totaling 162 individuals, or $45.76 \%$. The smallest group of people came from the faculty of nursing and represented $0.85 \%$ of the sample group, a total of three people. Computer business was the subject with the highest representation at 46 individuals $(12.99 \%)$, while the academic disciplines of fine arts, painting and the tourism industry and service management had the lowest representation of 2 people $(0.56 \%)$.

\subsection{Rating Scale Responses Obtained from First Year Undergraduate Students at Suratthani Rajabhat University Regarding Learning Responsibility}

Answers with a mean in the 'high' response category, which corresponded to the research hypothesis, showed that students place particular importance on learning and understanding new knowledge based on their own past experiences. This was the category with the highest positive response average from students. The lowest responses in the 'high' category were thorough sensibility and ability in working efficiently with others. The results when separated into groups are as follows:

1) Regarding classroom behaviour, students placed most importance on obeying and respecting the teacher, which they labelled in the 'high' category. The lowest regard was for attending class $\mathrm{n}$ time so that the teacher did not need to be strict, although this was also labelled 'high'. 
2) Regarding behaviour outside the classroom and independent study, students placed most importance on learning and understanding new knowledge based on their own experiences. This was labelled 'high'. The lowest importance was placed on diligence in order to achieve success, although this was also considered 'high'.

3) Regarding other behaviour related to studies, students placed most importance on self-honesty and honest to others. The lowest importance was thorough sensibility and ability in working efficiently with others, although this was also considered 'high'.

4.3 Comparison of Learning Responsibility of First-Year Undergraduate Students by Gender, Age, Religion, Faculty and Academic Discipline

The comparison of learning responsibility of first-year undergraduate students by gender, age, religion, faculty and academic discipline is summarized in the following table (Table 1).

Table 1. A summary of comparative analysis results by group: gender, age, religion, faculty and academic discipline

\begin{tabular}{|c|c|}
\hline Gender & $\begin{array}{l}\text { Female students were found to have higher levels of responsibility than males by a significance } \\
\text { level of } .05 \text {, which was consistent with the research hypothesis. }\end{array}$ \\
\hline Age & $\begin{array}{l}\text { Students over } 19 \text { years of age were found to have higher levels of responsibility than those under } \\
\text { or equal to } 19 \text { years of age by a significance level of } .05 \text {, which was consistent with the research } \\
\text { hypothesis. Students over nineteen years of age and nineteen-year old students had different } \\
\text { opinions about learning responsibility by a significance level of } .05 \text {. Other age groups were not } \\
\text { different by a significance level of } .05 \text {. }\end{array}$ \\
\hline Religion & $\begin{array}{l}\text { Those students who belonged to other faiths, including Christianity and Hinduism, had a higher } \\
\text { sense of responsibility toward learning than Buddhist students by a significance level of } .05 \text {, } \\
\text { which was consistent with the research hypothesis. Buddhist students and Muslim students had } \\
\text { different opinions about learning responsibility by a significance level of } .05 \text {. Other religious } \\
\text { groups were not different by a significance level of } .05 \text {. }\end{array}$ \\
\hline Faculty & $\begin{array}{l}\text { Students from the faculty of nursing had a higher level of learning responsibility than students } \\
\text { from other faculties, by a significance level of } .05 \text {, which was consistent with the research } \\
\text { hypothesis. When compared as pairs, it was found that students from the faculty of humanities } \\
\text { and social sciences had different opinions about learning responsibility from students from the } \\
\text { faculties of management science and science and technology by a significance level of } .05 \text {. Other } \\
\text { religious groups were not different by a significance level of } .05 \text {. }\end{array}$ \\
\hline $\begin{array}{l}\text { Academic } \\
\text { discipline }\end{array}$ & $\begin{array}{l}\text { Students from the academic discipline of science and technology had higher levels of learning } \\
\text { responsibility than students from the academic disciplines of health sciences and humanities and } \\
\text { social sciences by a significance level of } .05 \text {, which was consistent with the research hypothesis. } \\
\text { When compared as pairs, it was found that students from the academic discipline of humanities } \\
\text { and social sciences had different opinions about learning responsibility from students from the } \\
\text { academic discipline of science and technology by a significance level of .05. Other religious } \\
\text { groups were not different by a significance level of } .05 \text {. }\end{array}$ \\
\hline
\end{tabular}

\section{Discussion}

The level of learning responsibility among first-year undergraduate students at Suratthani Rajabhat University was found to have a high general average, which was consistent with the hypothesis of the research. This corresponds to the research of Kwanjai Unhawattanapaiboon (2008), which concerned responsible behavior of students in the service business faculty of Siam University. The research found that the students investigated had high levels of responsibility towards their studies, including high responsibility towards themselves and their actions. This also agrees with the research of Saowalak Sridaket (2008) at Sirindhorn College of Public Health, Khon Kaen Province, which found responsibility levels of all issues to be in the high category.

The results of this research suggested that students place particular importance on learning and understanding new knowledge based on their own past experiences. This idea matches with the concepts of Suwit Moonkam (2004), who explained that students must learn through practice and learn and understand new knowledge through their own past experiences because learning is a form of social endeavor. The lowest responses in the 
'high' category were thorough sensibility and ability in working efficiently with others, which relates to the work of Paradee Sritong (2000). Sritong found that for students to achieve success, they must have good levels of sensibility towards their actions and thoughts, including the ability to work efficiently with others.

Upon investigation of student attitudes towards responsibility in the classroom, outside the classroom and with relationship to self-study, it was clear that students place high importance on responsibility in all areas. This has an influence on studies, whether it is regarding discipline, pride, honesty, manners or thoroughness. As such, it is an attitude that should be adopted by all undergraduate students. Within the classroom, it was found that students placed importance on obeying and respecting the teacher, which is in line with the research of Ronnachai Boonleu (2005). Boonleu found that people have a duty towards their institution and teachers to be diligent, obedient, observe institutional regulations and take care of the institution. The importance placed on punctual attendance corresponds with the research of Pimpawee Supawiboon (2005), who studied behavioral adaptation of students entering their first undergraduate year of zoology for studying English communication 2. The findings revealed that students who attended their study program on time did so because they were interested in their studies. Aside from encouraging students to become interested in their subject material, institutions should provide a stimulating learning environment and systematic study. This is also in line with the research of Siripong Rakmai (2006), who studied the relationship between learning behavior and learning achievement of further education students. Rakmai's findings revealed that the majority of students have good attendance behavior and that this behavior has the highest relationship to learning achievement. The students who have better classroom attendance behavior will have better results than those with poorer behavior, who must adapt their practices both inside and outside the classroom.

In addition to learning new material on the basis of past experience in the classroom, students place importance on dedication to course material and excitement in learning. This also corresponds to Rakmai's results, as he identified the areas requiring adaptation to be independent search of supplementary study material outside the classroom. Importantly, Rakmai identified diligence in studies as being given the lowest importance for achieving success. This shows that students must search for supplementary study material and pay as much attention as they are able to their studies. This is equally in line with the theory of Kwanruedee Kamsonsat (1999), who equated the behavior of responsibility with the behavior of intention to study and diligence.

Regarding other areas, students placed importance on honesty to oneself and others. This is agreed upon by the findings of Paradee Sritong (2000), who stated that honesty is a quality of students that will affect learning responsibility. Although thorough sensibility and ability in working efficiently with others were assigned the lowest importance, there remains a need to recognize the right time and place to speak, sit, stand and walk in the classroom and outside. This is also concluded by Pensri Samranrat (2007), who studied the effectiveness of morals, ethics, values and thirteen qualities that should be instilled in students of professional diploma courses at Chiang Mai Polytechnic College. Samranrat concluded that in order to solve the moral and ethical problems of society, there must be a greater sense of occasion.

The results of comparison between gender, age, religion, faculty and academic discipline found a number of areas where the groups differed by a significance level of .05, which was consistent with the research hypothesis. This was also consistent with the findings of Pitploen Songwannapong (2007), which concluded that students of different genders had different senses of responsibility, which differed by a significance level of .05. Songwannapong also found that students in different departments had different attitudes towards learning responsibilities. This research found that female students had a greater sense of responsibility than male students, which is echoed by the research of Kwanjai Unhawattanapaiboon (2008), who also found the difference to have a significance level of .05. The findings of this research that suggested students older than nineteen years had higher levels of responsibility than those students of nineteen years or under was consistent with the work of Anuchit Ngamkajornwiwat (2006), which found that students of different ages had different levels of responsibility, with a significance level of .05 . Older students have a higher level of responsibility because of their greater experience and their greater knowledge of how to behave with different people. Regarding religion, it was found that Christian and Hindu students have higher levels of learning responsibility that Buddhist and Muslim students, which was also the case in the research of Sirintip Somkit (2008). Somkit identified a link between responsibility and social discipline and consideration, which are taught by the standards and practices of religion. Students in the faculty of nursing were found to have the highest level of responsibility in this research, which differed from other groups by a significance level of .05. These findings are different from those of Kwanjai Unhawattanapaiboon (2008), who concluded that students in all faculties had the same levels of responsibility. In terms of academic discipline, this research found those students in the department of science and technology to have greater levels of responsibility than students in other departments. This is due to the need 
for science and technology students to engage in high levels of theoretical and practical study and conduct their own independent research, which is important for the fostering of good professional ethics and public awareness that are encouraged by the university.

\section{References}

Boonleu, R. (2005). Research report into the development of ethical behavior and responsibility by using activities that evaluate real conditions and activities that evaluate norms. Bangkok: Office of Knowledge Management and Development Thailand.

Chainiyom, P. (1999). Study of the thoughts of teachers towards the teaching of responsibility and discipline by the procedures of related groups in educational institutes. Research Thesis, Academic discipline of Primary Education, Srinakharinwirot University.

Janbanjong, C. (1998). Education and the development of morals. Bangkok: Office of the National Education Commission.

Kaemmanee, T. (2003). Development of ethics, morals and values from the action theory. [in Thai.] Bangkok: Metitip Jamgat.

Kamsonsat, K. (1999). Study of behaviors of responsibility among undergraduate students at Mahidol University. Bangkok: Srinakharinwirot University.

Krejcie, R., \& Morgan, D. (1970). Determining sample size for research activities. Educational and Psychological Measurement, (30), 607-610.

Likert, R. (1932). A Technique for the Measurement of Attitudes. Archives of Psychology, 140, 1-55.

Moonkam, S. (2004). Strategies for teaching creative thinking. Bangkok: Hanghunsuan Jamgat, Pap-pim.

Ngamkajornwiwat, A. (2006). Social responsibility of vocational students: A case study of Pattani Province. Bangkok: National Institute of Development Administration.

Office for National Education Standards and Quality Assessment (Public Organization). (2004). 1999 Royal Education Act, amendments (volume 2), 2002. Bangkok: Prik Wan Graphic.

Office of the Higher Education Commission, Ministry of Education. (2008). The higher education development plan, volume 10, 2008-2011. Bangkok: The Office of the Higher Education Commission

Rakmai, S. (2006). Research report of the relationship between learning behavior and learning achievement of further education students (a case study of forecast business and research method at Dusit Thani College). Dusit Thani: Dusit Thani College.

Samranrat, P. (2007). Effectiveness of morals, ethics, values and 13 qualities that should be instilled in students of professional diploma courses at Chiang Mai Polytechnic College. Research Thesis, Chiang Mai University.

Scheffé, H. (1959). The Analysis of Variance. New York: Wiley.

Somkit, S. (2008). Factors affecting the learning responsibility of fourth level students at Promkiripittayakom School in Nakhon Sri Thammarat Province. Research Thesis, Srinakarinwirot University.

Songwannapong, P. (2007). Research report into the responsible behavior of students at the Rajamangala University of Technology, Suvarnabhumi, Nakhon Sri Ayutthaya Education Area, Wasukri Campus. Ayutthaya: Rajamangala University of Technology.

Sridaket, S. (2008). Research report into the ethical behavior of students on the Faculty of Public Health diploma curriculum and the highest professional diploma curriculum of the Sirindhorn College of Public Health Khon Kaen, Khon Kaen Province for the 2007 academic year. Khon Kaen: Sirindhorn College of Public Health Khon Kaen.

Sritong, P. (2000). The results of using programs to practice activities in psychology in order to develop responsibility in the undergraduate students of Mahasarakham University. Research Thesis, Department of Psychology, Mahasarakham University.

Supawiboon, P. (2005). Behavioral adaptation of students entering their first undergraduate year of zoology for studying English communication 2. Roi-Et: Office of Vocational Education Commission.

Unhawattanapaiboon, K. (2008). Research report into the study of responsible behavior of students in the service business faculty of Siam University. Bangkok: Siam University. 
Wirachai, N., Piromsombat, C., Na Wichian, S. (2007). Research report of the research and development of indicators of morals and ethics. Bangkok: Office of Knowledge Management and Development Thailand.

\section{Copyrights}

Copyright for this article is retained by the author(s), with first publication rights granted to the journal.

This is an open-access article distributed under the terms and conditions of the Creative Commons Attribution license (http://creativecommons.org/licenses/by/3.0/). 